Proceedings

\title{
Removal of Fluoride in Water with Mexican Natural Zeolite ${ }^{\dagger}$
}

\author{
Javier Sampedro-Duran ${ }^{1}$, Miguel Torres-Rodríguez ${ }^{2, *}$, Mirella Gutiérrez-Arzaluz ${ }^{2}$ and \\ Violeta Mugica-Álvarez ${ }^{2}$ \\ 1 Posgrados de la División de Ciencias Básicas e Ingeniería, Universidad Autónoma Metropolitana, \\ Mexico City 02200, Mexico; javi.sam.duran@gmail.com \\ 2 Departamento de Ciencias Básicas, Universidad Autónoma Metropolitana-Azcapotzalco, Mexico City 02200, \\ Mexico; gam@azc.uam.mx (M.G.-A.); vma@azc.uam.mx (V.M.-Á.) \\ * Correspondence: trm@azc.uam.mx; Tel.: +52-(1)-5553189570 \\ + Presented at the 2nd International Research Conference on Sustainable Energy, Engineering, Materials and \\ Environment (IRCSEEME), Mieres, Spain, 25-27 July 2018.
}

Published: 7 November 2018

\begin{abstract}
This work presents the results of the fluoride removal in water, through an adsorption process with the use of a natural Mexican zeolite conditioned with calcium, manganese or iron in a fixed bed column system. The XRD and FTIR characterization results demonstrated that the conditioning modifies the surface chemical composition of the zeolite and the SEM/EDS analysis corroborates the increase of the exchanged ions. The conditioning of the zeolite generated an increase in the adsorption capacity of fluorine, the best percentage of removal obtained from fluoride ions was $98 \%$, for a water with a concentration of $10 \mathrm{mg} \cdot \mathrm{L}^{-1}$ with the conditioned zeolite with iron.
\end{abstract}

Keywords: fluorine; natural zeolite; remove

\section{Introduction}

Nowadays, some small communities in different parts of the world and in particular in Mexico, are exposed to the intake of fluorides through water from wells of groundwater and springs [1]. In these communities, chronic water consumption with high concentrations of fluorides trigger health problems in the population such as dental and bone fluorosis [2]. In Mexico, in at least 6 of its states, high concentrations of fluoride in the water have been reported in different communities in the range of 3.8 to $17.7 \mathrm{mg} \cdot \mathrm{L}^{-1}$, far exceeding the limit established by the Mexican norm, NOM-127 -SSA1-1994 which establish as a maximum limit a concentration of $1.5 \mathrm{mg} \cdot \mathrm{L}^{-1}$ of fluorine in water for human consumption or as recommended by the World Health Organization (WHO) [3] $1 \mathrm{mg} \cdot \mathrm{L}^{-1}$. As an alternative for the removal of fluorides in water are the adsorption processes with materials that are efficient, low cost and easy to implement, natural zeolites meet these particularities and their different physical and chemical properties give these materials characteristics only that can be used $[4,5]$, particularly the properties of zeolites allows us to make a modification of its chemical composition surface on the ionic species present, in order to obtain a modified material that could be used as an adsorbent selective [6,7]. Mexico has large zeolitic deposits in several of its states and with different types of zeolites, particularly in this work a zeolite of the clinoptilolite type was used from a deposit in the place "Las Crucecitas" belonging to the municipality of Etla, in the central valley region of the state of Oaxaca in the southeast of Mexico. 


\section{Experimental}

The sample of zeolite, natural clinoptilolite, (ZC_N) was obtained directly from the deposit and later was crushed and sieved with a No.16 mesh to obtain an average particle diameter of $1.19 \mathrm{~mm}$, the crushed sample was subjected to a wash with deionized water to remove soluble material and impurities, it was subsequently left to dry at $100{ }^{\circ} \mathrm{C}$ for $24 \mathrm{~h}$. In order to have an appropriate adsorbent material, the ZC_N was subjected to an ion exchange process with a $2 \mathrm{M} \mathrm{NaCl}$ solution in a ratio of 1 $\mathrm{g}$ of zeolite per $10 \mathrm{~mL}$ of solution, with constant agitation for $24 \mathrm{~h}$ in a rotary evaporator at room temperature. The zeolite exchanged with sodium chloride was washed with abundant deionized water to remove the chlorine ions and finally allowed to dry at $100{ }^{\circ} \mathrm{C}$ for $24 \mathrm{~h}$. The sodium zeolite (ZC_Na) was exchanged with calcium or manganese ions by means of a solution of calcium nitrate or manganese of $0.01 \mathrm{M}$ concentration respectively and the $\mathrm{pH}$ of the solution was adjusted to a value of 5, the sample was placed in agitation in a $1 \mathrm{~g}$ of ZC_Na with $100 \mathrm{~mL}$ of exchange solution in the rotavapor for $24 \mathrm{~h}$, at room temperature, after the time elapsed the water was decanted and dried at $100{ }^{\circ} \mathrm{C}$ for $24 \mathrm{~h}$. The conditioning with $\mathrm{Fe}$ was carried out by the impregnation method by precipitation, $10 \mathrm{~g}$ of $\mathrm{ZC} \_\mathrm{Na}$ and $10 \mathrm{~mL}$ of a $0.5 \mathrm{M}$ iron nitrate solution were taken with $\mathrm{NH}_{4} \mathrm{OH}$, afterwards it was allowed to dry at room temperature for a period of $24 \mathrm{~h}$, finally to this it was washed with deionized water and allowed to dry at $100^{\circ} \mathrm{C}$.

Table 1. Adsorbent materials.

\begin{tabular}{cc}
\hline Sample & Description \\
\hline ZC_Na & Sodium Zeolite \\
ZC_Ca & Calcium Zeolite \\
ZC_Mn & Manganese Zeolite \\
ZC_Fe & Iron Zeolite \\
\hline
\end{tabular}

The natural sample and materials reported in Table 1, were characterized by different techniques such as: X-ray diffraction (XRD), in a Philip diffractometer, $X^{\prime}$ pert model, Fourier Transform Infrared Spectroscopy (FTIR), in a Varian spectrometer model Excalibur 3600, elemental chemical analysis (SEM/EDS) in a 55VP supra microscope, Carl Zeiss.

For the adsorption tests, a solution of $100 \mathrm{ppm}$ of fluorine with sodium fluoride was prepared, also two standards of $10 \mathrm{ppm}$ and $1 \mathrm{ppm}$ were prepared, and the determination of fluorides was carried out with an ExStik selective electrode model FL700. The fluoride removal was carried out in a downflow column system with a fixed bed of $3 \mathrm{~g}$ of conditioned zeolite (ZC_Ca, ZC_Mn or ZC_Fe) and $30 \mathrm{~mL}$ of water contaminated with fluorine with two concentrations; low concentration (LC) 1.5 $\mathrm{mg} \cdot \mathrm{L}^{-1}$ and high concentration (HC) $10 \mathrm{mg} \cdot \mathrm{L}^{-1}$ were used. The fluorine concentration was determined in the outlet water of the column after a contact period of $24 \mathrm{~h}$.

\section{Results and Discussion}

The results obtained from the natural zeolites and conditioned by the techniques of characterization by XRD, FTIR, shown in Figure 1A that presents the predominant zeolitic phase type clinoptilolite whose main diffraction angles pattern are: $9.7^{\circ}, 11.2^{\circ}, 15.6^{\circ}, 22.6^{\circ}, 25.3^{\circ}, 30.3^{\circ}, 32.3^{\circ}$ and $36.9^{\circ}$, being $9.7^{\circ}$ in the 2-theta angle the one with the highest intensity corresponding to the plane (020) (PDF 01-089-7538); in Figure 1B it is observed that the samples are slightly hydrated by bands that appear around 3600, 3400 and $1630 \mathrm{~cm}^{-1}(\mathrm{OH}$ group). The bands that appear around 1050, 790 and $450 \mathrm{~cm}^{-1}$ correspond to characteristic bands of the zeolitic structure, at $1012 \mathrm{~cm}^{-1}$ corresponds to an internal vibration of the stretching mode of the tetrahedron $\mathrm{TO}_{4}$, and the bands at 796 and $469 \mathrm{~cm}^{-1}$ correspond to the external vibration of the stretching mode of the OTO link. This corroborates that the structure of the zeolite is not modified or compromised with the conditioning treatment carried out. In region $780-520 \mathrm{~cm}^{-1}$ it is observed that bands of interaction for metals are present $(\mathrm{Ca}, \mathrm{Mn}$ and $\mathrm{Fe})$. The elemental analysis of the samples shown in Table 1 confirms the presence of manganese in 
the zeolite after conditioning and a 300\% increase in calcium content and $400 \%$ increase in iron content with respect to the material in its state natural.

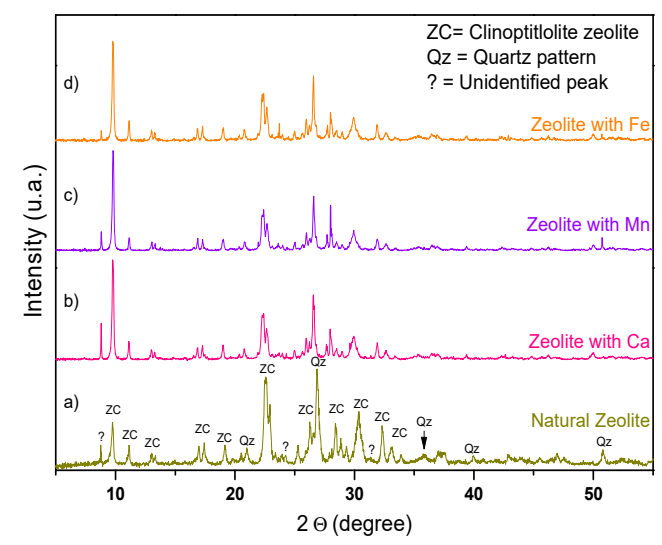

(a)

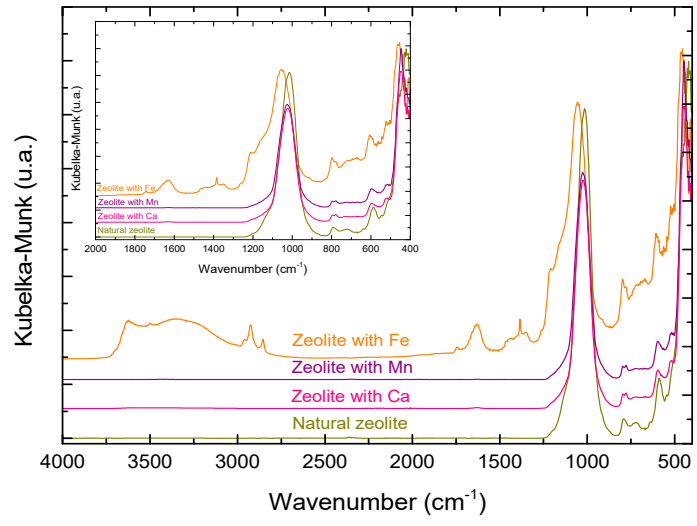

(b)

Figure 1. Natural zeolite and zeolites conditioned with calcium, manganese and iron, (a) XRD Diffraction, (b) FTIR spectroscopy.

The Table 2 shows the elemental composition of the natural zeolite and after being subjected to conditioning with iron and manganese and after the adsorption process. In these samples fluorine can be identified. These results show that the fluoride removed from the water is adsorbed on the zeolite. The ZC_Mn has $0.8 \mathrm{wt} \%$ fluorine in its composition and the ZC_Fe has a $3.31 \mathrm{wt} \%$, the best removal was obtained with the zeolite modified with iron.

Table 3, shows the initial concentration of fluoride in water low concentration (LC) $1.5 \mathrm{mg} \cdot \mathrm{L}^{-1}$, high concentrations (HC) $10 \mathrm{mg} \cdot \mathrm{L}^{-1}$, the concentration of fluoride at the exit of the column as well as the percentages of removal obtained for each sample zeolite and the milligrams of fluorine adsorbed per gram of zeolite $\left(\mathrm{mg}^{-1} \mathrm{~g}^{-1}\right)$, also are reported. The natural zeolite adsorbs $0.002 \mathrm{mg}$ of fluorine per gram of zeolite, for solutions with low concentrations of fluorine and for high concentrations an adsorption of $0.023 \mathrm{mg}$ of fluorine per gram is achieved, which represents a maximum removal percentage of $13 \%$. For the zeolite conditioned with calcium (ZC_Ca) obtained 53\% removal in low concentration and $28 \%$ removal in high concentration. Besides, the zeolite conditioned with manganese (ZC_Mn) obtained the highest fluoride removal at low concentrations compared to its homologs, decreasing the initial concentration up to $86 \%$ and at high concentrations it obtained a $44 \%$ removal. The zeolite conditioned with iron (ZC_Fe), showed the best results reaching $73 \%$ of removal in low concentrations and up to $98 \%$ of removal in water with an initial concentration of $10 \mathrm{mg} \cdot \mathrm{L}^{-1}$.

Table 2. Elemental composition of zeolites.

\begin{tabular}{ccccccc}
\hline \multirow{2}{*}{ Element } & ZC_N & ZC_Ca & ZC_Mn & ZC_Fe & ZC_Mn+F & ZC_Fe+F \\
\cline { 2 - 7 } Weight \% \\
\hline O K & 53.64 & 55.42 & 55.71 & 53.76 & 60.27 & 52.87 \\
Si K & 32.99 & 30.58 & 30.61 & 28.81 & 25.63 & 25.14 \\
Al K & 6.10 & 5.71 & 5.73 & 5.34 & 4.68 & 6.59 \\
Na K & 0.26 & 1.22 & 0.87 & 1.09 & 0.79 & 1.33 \\
Mg K & 0.57 & 0.56 & 0.53 & 0.25 & 0.49 & 0.19 \\
K K & 3.18 & 1.34 & 1.27 & 2.86 & 1.12 & 5.69 \\
Ca K & 1.27 & 4.8 & 1.04 & ---- & 0.77 & 0.36 \\
Mn K & ---- & ---- & 0.48 & --- & 0.30 & --- \\
Fe K & 1.75 & 0.38 & 0.47 & 7.88 & 0.34 & 4.14 \\
F K & ---- & ---- & ---- & --- & 0.80 & 3.31 \\
\hline
\end{tabular}


Table 3. Removal percentage and adsorption of fluorine ions with natural and conditioned zeolites.

\begin{tabular}{cccccc}
\hline ID & & $\begin{array}{c}\text { Initial Concentration } \\
\left(\mathbf{m g} \cdot \mathbf{L}^{-\mathbf{1}}\right)\end{array}$ & $\begin{array}{c}\text { Final Concentration } \\
\left.\mathbf{( m g} \cdot \mathbf{L}^{-\mathbf{1}}\right)\end{array}$ & $\begin{array}{c}\text { Removal } \\
\mathbf{( \% )}\end{array}$ & $\begin{array}{c}\text { Adsorption } \\
(\mathbf{m g ~ F}-\mathbf{g} \mathbf{~})\end{array}$ \\
\hline \multirow{2}{*}{ ZC_N } & LC & 1.5 & 1.3 & 13 & 0.002 \\
& HC & 10 & 8.7 & 13 & 0.013 \\
\hline \multirow{2}{*}{ ZC_Ca } & LC & 1.5 & 0.7 & 53 & 0.008 \\
& HC & 10 & 7.2 & 28 & 0.028 \\
\hline \multirow{2}{*}{ ZC_Mn } & LC & 1.5 & 0.2 & 86 & 0.013 \\
& HC & 10 & 5.6 & 44 & 0.044 \\
\hline \multirow{2}{*}{ ZC_Fe } & LC & 1.5 & 0.4 & 73 & 0.011 \\
& HC & 10 & 0.2 & 98 & 0.098 \\
\hline
\end{tabular}

\section{Conclusions}

It was determined that the natural clinoptilolite zeolite from Etla, in the central valley region of the state of Oaxaca, Mexico, has an intrinsic capacity for the removal of fluorine in water up to 0.023 $\mathrm{mg} \cdot \mathrm{g}^{-1}$, and the conditioning of this material with calcium, manganese or iron significantly increases this removal capacity, being the zeolite conditioning with iron, the best material because the results showed that increasing more than $80 \%$ the removal capacity of the zeolite in relation to its natural state. This means that even having water with concentrations of $10 \mathrm{mg} \cdot \mathrm{L}^{-1}$ this system is able to reduce this concentration well below the limit established by the Mexican norm and the limit from WHO.

This system, column with fixed bed of natural adsorbent conditioned with $\mathrm{Fe}$, result in a conventional filter that does not require complex specifications in its implementation, so it is a good option for use in the water treatment in marginalized areas of Mexico.

Author Contributions: M.G.-A. and M.T.-R. conceived of and designed the experiments and analyzed the data, J.S.-D. performed the experiments and V.M.-Á. wrote the paper.

Acknowledgments: Sampedro thanks the CONACyT scholarship and the co-authors thank the Divisional Electronic Microscopy Laboratory of the UAM-A.

Conflicts of Interest: The authors declare no conflict of interest.

\section{References}

1. Armienta, M.A. Arsenic and Fluoride in the groundwater of Mexico. Environ. Geochem. Health 2008, 30, 345353.

2. Agencia para Sustancias Tóxicas y el Registro de Enfermedades, División de Toxicología. Fluorides, Hydrogen Fluoride, and Fluorine; Division of Toxicology: Atlanta, GA, USA, 2003.

3. Liteplo, R.; Gomes, R.; Howe, P.; Malcolm, H. Fluorides; Environmental Health Criteria 227; World Health Organization: Geneva, Switzerland, 2002.

4. Sun, Y.; Fang, Q.; Dong, J.; Cheng, X.; Xu, J. Removal of fluoride from drinking water by natural stilbite zeolite modified with Fe (III). Desalination 2011, 277, 121-127.

5. Zhang, Z.; Tan, Y.; Zhong, M. Desflourination of wastewater by calcium chloride modified natural zeolite. Desalination 2011, 276, 246-252.

6. Cao, M. Treatment of High Fluorine Water by Zeolite. Appl. Mech. Mater. 2014, 685, 468-472.

7. Cota, A.M.; Meza, M.B.; Ramírez, M.V.; Munguía, J.C.; Salazar, J.V. Eliminación de flúor en agua potable utilizando zeolita natural (clinoptilolita). Rev. Cienc. Biol. Salud XV 2012, 2, 10-14.

(C) 2018 by the authors. Licensee MDPI, Basel, Switzerland. This article is an open access article distributed under the terms and conditions of the Creative Commons Attribution (CC BY) license (http://creativecommons.org/licenses/by/4.0/). 